\title{
ANALISIS PENGARUH ENTREPRENEURIAL LEADERSHIP DAN MOTIVASI KERJA TERHADAP KINERJA KARYAWAN PT TIGA PUTRA ADHI MANDIRI
}

\author{
Nike Fransiska; Karyana Hutomo \\ Management Department, School of Business Management, BINUS University \\ Jln. K.H. Syahdan No. 9, Palmerah, Jakarta Barat 11480 \\ khutomo@binus.edu
}

\begin{abstract}
The purpose of this study is to discover and understand how much the influence of entrepreneurial leadership and working motivation on employee performance at PT Tiga Putra Adhi Mandiri. This study used quantitative approach which used survey method with questionnaire as a tool to get the data, where the populations were 46 respondents. The analysis method that is used in this study is simple regression and multiple regressions. These analyses is used to find out how much the influence of entrepreneurial leadership and working motivation variables as independent variable on employee performance at PT Tiga Putra Adhi Mandiri as a dependent variable. The result of this study is entrepreneurial leadership had 40,3\% significant influence on employee performance at PT Tiga Putra Adhi Mandiri and motivation also had 40,8\% significant influence on employee performance at PT Tiga Putra Adhi Mandiri. While both entrepreneurial leadership and working motivation had 47,3\%. Significant influence on employee performance at PT Tiga Putra Adhi Mandiri. Seeing each variable had significant influence then researcher recommend to increase the entrepreneurial leadership and working motivation so that the employee performance also increases and the company goal can be achieved.
\end{abstract}

Keywords: entrepreneurial leadership, working motivation, and employee performance

\begin{abstract}
ABSTRAK
Tujuan penelitian ini adalah untuk mengetahui dan memahami seberapa besar pengaruh entrepreneurial leadership dan motivasi kerja terhadap kinerja karyawan PT Tiga Putra Adhi Mandiri. Penelitian ini menggunakan pendekatan kuantitatif dimana menggunakan metode survey dengan kusioner sebagai alat untuk memperoleh data, dimana populasi yang digunakan adalah sebanyak 46 responden. Metode analisis yang digunakan dalam penelitian ini adalah regresi sederhana dan regresi berganda. Analisis ini digunakan untuk mengetahui seberapa besar pengaruh variabel entrepreneurial leadership dan motivasi kerja sebagai variabel independen terhadap kinerja karyawan PT Tiga Putra Adhi Mandiri sebagai variabel dependen. Hasil yang dicapai dalam penelitian ini adalah entrepreneurial leadership berpengaruh secara signifikan sebesar 40,3\% terhadap kinerja karyawan PT Tiga Putra Adhi Mandiri dan motivasi berpengaruh secara signifikan sebesar 40,83\%. terhadap kinerja karyawan PT Tiga Putra Adhi Mandiri. Sedangkan secara keseluruhan, entrepreneurial leadership dan motivasi kerja berpengaruh secara signifikan sebesar 47,3\%. terhadap kinerja karyawan PT Tiga Putra Adhi Mandiri. Melihat masing-masing variabel memiliki pengaruh yang signifikan maka penulis menyarankan untuk meningkatkan entrepreneurial leadership dan motivasi kerja agar kinerja karyawan meningkat sehingga tujuan perusahaan dapat tercapai.
\end{abstract}

Kata kunci: entrepreneurial leadership, motivasi kerja, dan kinerja karyawan 


\section{PENDAHULUAN}

Menurut hasil survey mengenai kepuasan karyawan yang bertajuk Global Workforce Study (GWS) 2012 yang dilakukan oleh Towers Watson, hampir dua per pertiga karyawan di Indonesia tidak memiliki hubungan yang kuat pada perusahaan. Yang lebih mengkhawatirkan lagi adalah sekitar $38 \%$ dari karyawan yang tidak memiliki keterkaitan, cenderung akan meninggalkan pekerjaan mereka dalam dua tahun (portalhr, 2012). Seorang entrepreneur yang baik, harus bisa menjadi seorang pemimpin yang mampu mempengaruhi para karyawan dalam bekerja sehingga karyawan dapat menunculkan ide-ide dan kinerja terbaik. Seorang pemimpin juga harus dapat melakukan pendekatan yang efektif bagi para bawahannya, agar karyawan merasa dihargai sehingga secara tidak langsung mereka akan memberikan kontribusi penuh terhadap kinerja perusahaan.

Peran Entrepreneurial Leadership sangatlah penting untuk diterapkan dalam suatu kewirausahaan, karena hal itu merupakan salah satu kunci keberhasilan dalam perusahaan. Kepemimpinan adalah kekuatan utama yang dibutuhkan untuk melakukan perubahan yang berhasil. Pemimpin harus memberdayakan karyawannya untuk merealisasikan visi. Salah satu faktor penting yang berpengaruh dalam keberhasilan seorang entrepreneur dalam mengerakkan orang lain dalam mencapai tujuan yang telah ditetapkan perusahaannya adalah memberikan motivasi.

Menurut para ahli, di era perubahan yang cepat, para manajer dan pemimpin dituntut untuk lebih entrepreneurial. Kepemimpinan adalah kekuatan utama yang dibutuhkan untuk berhasil melakukan perubahan. Pemimpin harus memberdayakan karyawannya untuk merealisasikan visi.

\section{Rumusan Masalah}

Penelitian ini dilakukan untuk menjawab pertanyaan; (1) Apakah ada pengaruh yang signifikan antara Entrepreneurial Leadership terhadap Kinerja Karyawan PT Tiga Putra Adhi Mandiri? (2) Apakah ada pengaruh yang signifikan antara Motivasi Kerja terhadap Kinerja Karyawan PT Tiga Putra Adhi Mandiri (3) Apakah ada pengaruh yang signifikan antara Entrepreneurial Leadership dan Motivasi Kerja terhadap Kinerja Karyawan PT Tiga Putra Adhi Mandiri?

\section{Tujuan Penelitian}

Penelitian ini bertujuan untuk; (1) Mengetahui dan memahami pengaruh Entrepreneurial Leadership terhadap Kinerja Karyawan PT Tiga Putra Adhi Mandiri. (2) Mengetahui dan memahami pengaruh Motivasi Kerja terhadap Kinerja Karyawan PT Tiga Putra Adhi Mandiri. (3) Mengetahui dan memahami pengaruh Entrepreneurial Leadership dan Motivasi kerja terhadap Kinerja Karyawan PT Tiga Putra Adhi Mandiri.

\section{Kajian Pustaka}

Menurut J. Winardi (2008) Entrepreneurial Leadership adalah Entrepreneur yang inovatif berekperimen secara agresif, dan mereka terampil mempraktekkan transformasi-tranformasi kemungkinan-kemungkinan atraktif. Terdapat lima dimensi di dalam perusahaan yang dijalankan dengan Entrepreneurial Leadership, yaitu: (1) Orientasi yang didorong persepsi peluang, (2) Komitmen terhadap peluang-peluang, (3) Komitmen sumber-sumber daya, (4) Pengendalian sumbersumber daya, dan (5) Visi yang Realistik.

Menurut Robbins (2007), Motivasi adalah proses yang ikut menentukan intensitas, arah, dan ketekunan individu dalam usaha mencapai sasaran. Menurut Frederick Herzberg dalam Robbins (2007) ada dua jenis faktor yang mempengarhi motivasi kerja, yaitu (1) faktor instrinsik yang terdiri 
dari: Tanggung Jawab (Responsibility), Kemajuan (Advancement), Pekerjaan Itu Sendiri (the work itself), Pencapaian (achievement), Pengakuan (Recognition), dan (2) faktor ekstrinsik yang terdiri dari: Kebijakan dan Administrasi perusahaan (company policy and administration), Kondisi kerja (working condition), Gaji dan Upah (wages and salaries), Hubungan Antar Pribadi (interpersonal relation), Kualitas supervisi (Quality supervisor).

Menurut Mangkunegara (2007), Kinerja Karyawan adalah hasil kerja secara kualitas dan kuantitas yang dicapai oleh seseorang karyawan dalam melaksanakan tugasnya sesuai dengan tanggung jawab yang diberikan kepadanya. Menurut Keith Davis dalam Mangkunegara (2007) faktorfaktor yang mempengaruhi kinerja adalah faktor kemampuan (ability) dan faktor motivasi (motivation).

\section{METODE}

\section{Metode yang digunakan}

Secara umum, penelitian ini merupakan penelitian asosiatif dimana tujuan dari penelitian ini untuk mengetahui hubungan antara dua variabel atau lebih dan tingkat ketergantungan antara variabelvariabel tersebut. Time Horizon yang digunakan dalam penelitian ini adalah cross sectional dimana pengambilan data dilakukan hanya pada satu waktu dan satu kali dan bertujuan untuk mencari hubungan antara variabel independen dan variabel dependen.

\section{Teknik Pengumpulan Data}

Teknik Pengumpulan Data yang digunakan dalam penelitian ini adalah: (1) Observasi (Pengamatan), peneliti melakukan pengamatan langsung terhadap kinerja yang dilakukan karyawan PT Tiga Putra Adhi Mandiri. (2) Kuesioner (Angket), menurut Sugiyono (2012) kuesioner merupakan teknik pengumpulan data yang dilakukan dengan cara memberikan seperangkat pertanyaan atau pertanyaan tertulis kepada responden untuk dijawab. Peneliti akan membagikan kuesioner kepada semua karyawan PT Tiga Putra Adhi Mandiri untuk diisi dan kemudian dijadikan sumber data dalam penelitian. (3) Studi Pustaka, peneliti melakukan studi pustaka dengan membaca referensi, seperti buku catatan selama perkuliahan, buku cetak dan lain-lain yang berkaitan dengan penelitian ini.

\section{Jenis Dan Sumber Data}

Jenis data yang digunakan dalam penelitian ini berupa jenis data kuantitatif. Dengan demikian, penelitian ini menggunakan data yang dilaporkan sendiri oleh responden secara organisasional di mana responden akan memberikan respon verbal dan atau respon tertulis sebagai tanggapan atas pertanyaan yang diberikan oleh peneliti. Sumber data dalam penelitian ini diperoleh dari data primer . Data primer yang akan dikumpulkan peneliti berupa jawaban / isian kuesioner peneliti dengan basis konten berupa opini/persepsi responden.

Sedangkan data sekunder yang dibutuhkan hanyalah catatan, arsip, atau pun laporan historis dari perusahaan atau instansi yang berkaitan dengan penelitian ini. Data sekunder tidak menjadi bagian dari proses analisis secara kuantitatif, namun menjadi bahan awal dalam mengumpulkan data dan masukan tambahan dalam implikasi manajerial. 


\section{Kerangka Pemikiran}

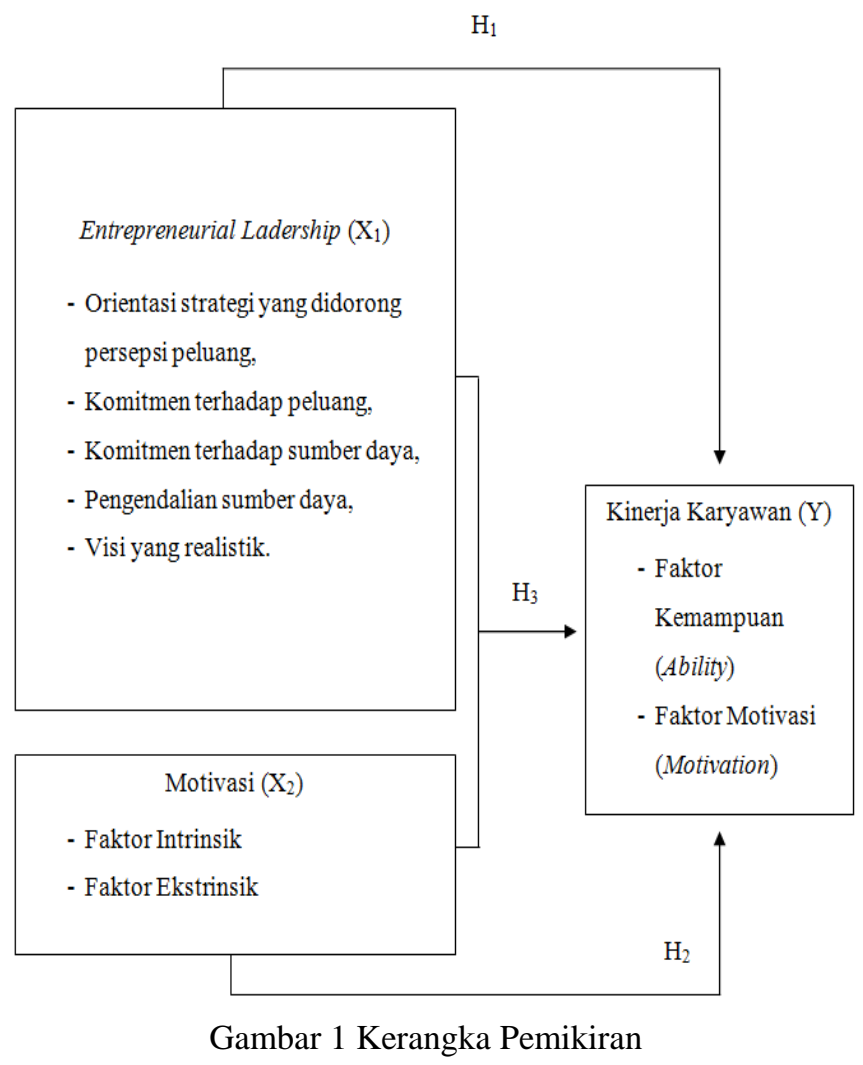

\section{Hipotesis}

Hipotesis 1

Ho : Tidak ada pengaruh antara Entrepreneurial Leadership terhadap Kinerja Karyawan PT Tiga Putra Adhi Mandiri.

Ha : Ada pengaruh antara Entrepreneurial Leadership terhadap Kinerja Karyawan PT Tiga Putra Adhi Mandiri.

Hipotesis 2

Ho : Tidak ada pengaruh antara Motivasi Kerja terhadap Kinerja Karyawan.

Ha : Ada pengaruh antara Motivasi Kerja terhadap Kinerja Karyawan.

Hipotesis 3

Ho : Tidak ada pengaruh antara Entrepreneurial Leadership dan Motivasi Kerja terhadap Kinerja Karyawan PT Tiga Putra Adhi Mandiri.

$\mathrm{H}_{1}$ : Ada pengaruh antara Entrepreneurial Leadership dan Motivasi Kerja terhadap Kinerja Karyawan PT Tiga Putra Adhi Mandiri. 


\section{HASIL DAN PEMBAHASAN}

\section{Hasil Uji Validitas dan Reliabilitas}

Hasil uji validitas dan reliabilitas yang dilakukan pada Variabel Entrepreneurial Leadership $\left(\mathrm{X}_{1}\right)$ dengan diukur melalui butir pertanyaan $1,2,3,4,5,6,7,8,9$, menggunakan bantuan program SPSS diperoleh hasil sebagai berikut:

Tabel 1 Hasil Uji Validitas Variabel Entrepreneurial Leadership $\left(\mathrm{X}_{1}\right)$

\begin{tabular}{ccccc}
\hline Butir Pertanyaan & $\mathbf{r}_{\text {hitung }}$ & Tanda & $\mathbf{r}_{\text {tabel }}$ & Keterangan \\
\hline 1) & 0,746 & $>$ & 0,25 & Valid \\
2) & 0,736 & $>$ & 0,25 & Valid \\
3) & 0,355 & $>$ & 0,25 & Valid \\
4) & 0,580 & $>$ & 0,25 & Valid \\
5) & 0,614 & $>$ & 0,25 & Valid \\
6) & 0,593 & $>$ & 0,25 & Valid \\
7) & 0,492 & $>$ & 0,25 & Valid \\
8) & 0,746 & $>$ & 0,25 & Valid \\
9) & 0,736 & $>$ & 0,25 & Valid \\
\hline
\end{tabular}

Pada tabel 1, dapat dilihat hasil uji validitas pertanyaan mengenai Entrepreneurial Leadership. Nilai $r_{\text {hitung }}$ lebih besar dari nilai $r_{\text {tabel }}(0,25)$ sehingga dapat dikatakan butir pertanyaan $1,2,3,4,5,6$, 7, 8, dan 9 dapat dikatakan valid. Untuk menguji reliabilitas data melalui hasil perhitungan SPSS, diperoleh nilai Cronbach Alpha = 0,873 > 0,26 ( $\mathrm{r}_{\text {tabel }}$ ), maka dapat disimpulkan data reliabel.

Hasil uji validitas dan reliabilitas yang dilakukan pada Variabel Motivasi Kerja $\left(\mathrm{X}_{2}\right)$ dengan diukur melalui butir pertanyaan 1, 2, 3, 4, 5, 6, 7, 8, 9, 10, menggunakan bantuan program SPSS diperoleh hasil sebagai berikut:

Tabel 2 Uji Validitas Variabel Motivasi Kerja $\left(\mathrm{X}_{2}\right)$

\begin{tabular}{ccccc|}
\hline Butir Pertanyaan & $\mathbf{r}_{\text {hitung }}$ & Tanda & $\mathbf{r}_{\text {tabel }}$ & Keterangan \\
\hline 1) & 0,399 & $>$ & 0,25 & Valid \\
2) & 0,577 & $>$ & 0,25 & Valid \\
3) & 0,418 & $>$ & 0,25 & Valid \\
4) & 0,520 & $>$ & 0,25 & Valid \\
5) & 0,547 & $>$ & 0,25 & Valid \\
6) & 0,450 & $>$ & 0,25 & Valid \\
7) & 0,328 & $>$ & 0,25 & Valid \\
8) & 0,600 & $>$ & 0,25 & Valid \\
9) & 0,442 & $>$ & 0,25 & Valid \\
10) & 0,498 & $>$ & 0,25 & Valid \\
\hline
\end{tabular}

Pada tabel 2, dapat dilihat hasil uji validitas pertanyaan mengenai motivasi kerja. Nilai $\mathrm{r}_{\text {hitung }}$ lebih besar dari nilai $\mathrm{r}_{\text {tabel }}(0,25)$ sehingga dapat dikatakan butir pertanyaan $1,2,3,4,5,6,7,8,9$, dan 10 dapat dikatakan valid. Untuk menguji reliabilitas data melalui hasil perhitngan SPSS, diperoleh nilai Cronbach Alpha $=0,798>0,25\left(\mathrm{r}_{\text {tabel }}\right)$, maka dapat disimpulkan data reliabel.

Hasil uji validitas dan reliabilitas yang dilakukan pada Variabel Kinerja Karyawan (Y) dengan diukur melalui butir pertanyaan 1, 2, 3, 4, 5, 6, 7, 8, 9, menggunakan bantuan program SPSS diperoleh hasil sebagai berikut: 
Tabel 3 Uji Validitas Variabel Kinerja Karyawan (Y)

\begin{tabular}{ccccc}
\hline Butir Pertanyaan & $\mathbf{r}_{\text {hitung }}$ & Tanda & $\mathbf{r}_{\text {tabel }}$ & Keterangan \\
\hline 1) & 0,535 & $>$ & 0,25 & Valid \\
2) & 0,455 & $>$ & 0,25 & Valid \\
3) & 0,420 & $>$ & 0,25 & Valid \\
4) & 0,274 & $>$ & 0,25 & Valid \\
5) & 0,510 & $>$ & 0,25 & Valid \\
6) & 0,529 & $>$ & 0,25 & Valid \\
7) & 0,564 & $>$ & 0,25 & Valid \\
8) & 0,510 & $>$ & 0,25 & Valid \\
9) & 0,328 & $>$ & 0,25 & Valid \\
\hline
\end{tabular}

Pada tabel 3, dapat dilihat hasil uji validitas pertanyaan mengenai kinerja karyawan PT Tiga Putra Adhi Mandiri. Nilai $\mathrm{r}_{\text {hitung }}$ lebih besar dari nilai $\mathrm{r}_{\text {tabel }}(0,25)$ sehingga dapat dikatakan butir pertanyaan 1, 2, 3, 4, 5, 6, 7, 8, dan 9 dapat dianggap valid. Untuk menguji reliabilitas data melalui hasil perhitungan SPSS, diperoleh nilai Cronbach Alpha $=0,772>0,25$ ( $\left.\mathrm{r}_{\text {tabeel }}\right)$, maka dapat disimpulkan data reliabel.

\section{Uji Normalitas}

Hasil uji normalitas yang dilakukan pada Data Entrepreneurial Leadership $\left(\mathrm{X}_{1}\right)$ menggunakan bantuan program SPSS diperoleh Sig. Entrepreneurial Leadership adalah 0.200, maka data Entrepreneurial Leadership $\left(\mathrm{X}_{1}\right)$ berdistribusi normal.

Hasil uji normalitas yang dilakukan pada Data Motivasi Kerja $\left(\mathrm{X}_{2}\right)$ menggunakan bantuan program SPSS diperoleh Sig. Motivasi Kerja adalah 0.200, maka data Motivasi Kerja $\left(\mathrm{X}_{2}\right)$ berdistribusi normal.

Hasil uji normalitas yang dilakukan pada Data Kinerja Karyawan (Y) menggunakan bantuan program SPSS diperoleh Sig. Motivasi Kerja adalah 0.082, maka data Kinerja Karyawan (Y) berdistribusi normal.

\section{Uji Regresi Sederhana}

Uji regresi sederhana pada Analisis Pengaruh Entrepreneurial Leadership $\left(\mathrm{X}_{1}\right)$ terhadap Kinerja Karyawan (Y) menunjukkan besarnya pengaruh faktor Entrepreneurial Leadership terhadap Kinerja Karyawan PT Tiga Putra Adhi Mandiri adalah sebesar 40,3\%, dan sisanya 59,7\% dipengaruhi faktor lain yang tidak dijelaskan dalam penelitian ini.

Uji regresi sederhana pada Analisis Pengaruh Motivasi Kerja $\left(\mathrm{X}_{2}\right)$ terhadap Kinerja Karyawan (Y) menunjukkan besarnya pengaruh faktor Motivasi Kerja $\left(\mathrm{X}_{2}\right)$ terhadap Kinerja Karyawan PT Tiga Putra Adhi Mandiri (Y) adalah sebesar 40,8\% dan sisanya 59,2\% dipengaruhi faktor lain yang tidak dijelaskan dalam penelitian ini.

\section{Uji Regresi Berganda}

Uji regresi berganda pada Analisis Pengaruh Motivasi Kerja $\left(\mathrm{X}_{2}\right)$ terhadap Kinerja Karyawan (Y) menunjukkan besarnya pengaruh faktor Entrepreneurial Leadership $\left(\mathrm{X}_{1}\right)$ dan Motivasi Kerja $\left(\mathrm{X}_{2}\right)$ terhadap Kinerja Karyawan PT Tiga Putra Adhi Mandiri (Y) adalah sebesar 47,3\% dan sisanya 52,7\% dipengaruhi faktor lain yang tidak dijelaskan dalam penelitian ini. 


\section{Pembahasan dan Pemecahan Masalah}

Dari hasil yang telah dilakukan dengan menggunakan software SPSS versi 16.0 dapat diketahui apakah terdapat pengaruh dari masing-masing variabel bebas (Entrepreneurial leadersip dan motivasi Kerja) terhadap variabel terikat (Kinerja karyawan PT Tiga Putra Adhi Mandiri). Hasil dari penelitian ini dapat dilihat melalui persamaan regresi sederhana dan persamaan regresi berganda.

Dari persamaan regresi sederhana dapat dilihat bahwa variabel entrepreneurial leadership memberikan pengaruh sebesar 40,3\% terhadap kinerja karyawan. Entrepreneurial leadership mempengaruhi dan menentukan tinggi rendahnya kinerja karyawan pada PT Tiga Putra Adhi Mandiri. Hal ini menunjukkan bahwa semakin tinggi entrepreneurial leadership diterapkan pemimpin dalam perusahaan akan meningkatkan kinerja karyawan. Oleh karena itu entrepreneurial leadership perlu ditingkatkan guna meningkatkan kinerja karyawan sehingga karyawan dapat bekerja secara optimal dan mencapai produktivitas yang diinginkan perusahaan.

Dari persamaan regresi sederhana dapat dilihat bahwa variabel motivasi kerja memberikan pengaruh sebesar 40,8 terhadap kinerja karyawan. Motivasi Kerja mempengaruhi dan menentukan tinggi rendahnya kinerja karyawan pada PT Tiga Putra Adhi Mandiri. Hal ini menunjukkan bahwa semakin tinggi motivasi kerja yang diterima karyawan dalam bekerja akan menghasilkan peningkatan pada kinerja karyawan. Oleh karena itu motivasi kerja perlu ditingkatkan guna meningkatkan kinerja karyawan sehingga perusahaan dapat mencapai tujuan yang telah direncanakan dan diharapkan.

Dari persamaan regresi berganda dapat dilihat bahwa entrepreneurial leadership dan motivasi kerja berpengaruh secara signifikan terhadap kinerja karyawan sebesar 47,3\%. Hal ini menunjukkan bahwa kinerja karyawan PT Tiga Putra Adhi Mandiri dipengaruhi oleh entrepreneurial leadership dan motivasi kerja. Jika entrepreneurial leadership dan motivasi kerja mampu dijalankan perusahaan dengan optimal maka akan mampu meningkatkan kinerja PT Tiga Putra Adhi Mandiri. Oleh karena itu perusahaan harus meningkatkan entrepreneurial leadership dan motivasi kerja untuk mendapatkan kinerja yang optimal sehingga memberikan keuntungan untuk perusahaan.

\section{SIMPULAN}

Berdasarkan pada hasil analisa dan pengolahan data mengenai analisa pengaruh entrepreneurial leadership dan motivasi kerja PT Tiga Putra Adhi Mandiri, maka dapat ditarik kesimpulan bahwa (1) Variabel entrepreneurial leadership memberikan pengaruh sebesar 40,3\% terhadap kinerja karyawan. Entrepreneurial leadership mempengaruhi dan menentukan tinggi rendahnya kinerja karyawan pada PT Tiga Putra Adhi Mandiri. Hal ini menunjukkan bahwa semakin tinggi entrepreneurial leadership diterapkan pemimpin dalam perusahaan akan meningkatkan kinerja karyawan. (2) Variabel motivasi kerja memberikan pengaruh sebesar 40,8\% terhadap kinerja karyawan. Motivasi Kerja mempengaruhi dan menentukan tinggi rendahnya kinerja karyawan pada PT Tiga Putra Adhi Mandiri. Hal ini menunjukkan bahwa semakin tinggi motivasi kerja yang diterima karyawan dalam bekerja akan menghasilkan peningkatan pada kinerja karyawan. (3) Variabel entrepreneurial leadership dan motivasi kerja secara bersama-sama berpengaruh secara signifikan terhadap kinerja karyawan sebesar 47,3\%. Hal ini menunjukkan bahwa kinerja karyawan PT Tiga Putra Adhi Mandiri dipengaruhi oleh entrepreneurial leadership dan motivasi kerja.

Berdasarkan hasil penelitian yang diperoleh dari analisa diatas, maka saran-saran yang dapat diberikan kepada PT Tiga Putra Adhi Mandiri adalah: (1) Pemimpin harus memantau perkembangan karyawannya. (2) Pemimpin sebaiknya memberikan arahan dan pelatihan guna meningkatkan kemampuan dan keterampilan karyawan. (3) Pemimpin sebaiknya memberikan kesempatan bagi 
karyawan untuk mendapatkan timbal balik, seperti penghargaan atas prestasi kerja yang telah dicapai. (4) Perusahaan sebaiknya memberikan lingkungan kerja yang kondusif bagi karyawan untuk memotivasi karyawan agar menghasilkan kinerja yang lebih baik.

\section{DAFTAR PUSTAKA}

Global Workforce Study (2012). Towers Watson. Diakses dari http://www.portalhr.com/berita/globalworkforce-study-2012-mencengangkan-23-karyawan-disengaged/

Mangkunegara, A. A. A. P. (2007). Manajemen sumber daya manusia perusahaan. Bandung: Remaja Rosda.

Robbins, S. P., Judge, T. (2007). Perilaku Organisasi. Jakarta: Salemba Empat.

Sugiyono. (2012). Metode Penelitian Bisnis. Bandung: CV. Alfabeta.

Winardi, J. (2008). Entrepreneur dan Entrepreneurship. Jakarta: Prenada. 